\title{
Use of colonic eicosanoid concentrations as predictors of relapse in ulcerative colitis: double blind placebo controlled study on sulphasalazine maintenance treatment
}

\author{
K LAURITSEN, L STÆRK LAURSEN, K BUKHAVE, AND J RASK-MADSEN \\ From the Department of Medical Gastroenterology, Odense University Hospital, Odense and Sections of \\ Gastroenterology, Department of Medicine C, Herlev Hospital and Department of Medicine B, Bispebjerg \\ Hospital, University of Copenhagen, Copenhagen, Denmark
}

SUMmary To establish whether concentrations of eicosanoids determined by equilibrium in vivo dialysis of faeces and equilibrium in vivo dialysis of rectum might predict a relapse in ulcerative colitis, 23 patients with completely inactive disease, maintained on sulphasalazine, stopped treatment and entered a prospective study. Concentrations of prostaglandin $E_{2}$ were determined by radioimmunoassay on purified faecal and rectal dialysates at entry, at two weeks, and at two, six, and 12 months. If the above concentrations exceeded control concentrations $(0.5 \mathrm{ng} / \mathrm{ml}$ and $1.0 \mathrm{ng} / \mathrm{ml}$ in faecal and rectal fluid, respectively) at any study day, the patient was allocated at random to double blind treatment with sulphasalazine $2 \mathrm{~g} /$ day, or placebo for six months. A relapse, defined as recurrence of symptoms accompanied by endoscopic inflammation occurred in none of six and in four of five patients allocated to sulphasalazine and placebo, respectively $(p<0 \cdot 05)$. In no case a normal rectal prostaglandin $E_{2}$ concentration was associated with a relapse in the short term, but only two of 12 patients observed passively remained in remission. In retrospect, leucotriene $B_{4}$ was a less sensitive predictor of relapse than prostaglandin $E_{2}$. We conclude that raised concentrations of prostaglandin $E_{2}$ in rectal dialysis fluid identify patients with a substantial risk of relapse.

Since it was originally reported in a controlled trial ${ }^{1}$ that sulphasalazine (SAZ) reduces the recurrence rate in patients with ulcerative colitis (UC) this drug has become the mainstay of maintenance therapy for the prevention of relapse in patients with UC. ${ }^{23}$ The duration of SAZ therapy, given for more than one year, however, remains controversial and two early studies gave conflicting results. ${ }^{45}$ Despite several subsequent studies have shown higher relapse rates in patients discontinuing SAZ treatment for other remedies $^{6-9}$ current practice, as to how long to continue treatment, often rests on 'personal clinical experience' - also because no clinical or laboratory

Address for correspondence: Dr Jørgen Rask-Madsen, Section of Gastroenterology, Department of Medicine B, Bispebjerg Hospital, DK-2400 Copenhagen NV, Denmark.

Received for publication 7 July 1988. indices have been shown to improve decision making.

The concentration of prostaglandin $\mathrm{E}_{2}\left(\mathrm{PGE}_{2}\right)$ in rectal dialysis fluid, obtained by the method of equilibrium in vivo dialysis of rectum, was shown recently to be a sensitive marker of disease activity. ${ }^{10}$ Furthermore, it was suggested that a rise in $\mathrm{PGE}_{2}$ concentrations in faecal dialysates, obtained by the method of equilibrium in vivo dialysis of faeces in patients with inactive UC, precedes the development of clinical symptoms in those who later experience a relapse. ${ }^{11}$ The purpose of the present study was to establish whether prospective determinations of $\mathrm{PGE}_{2}$ concentrations in faecal and rectal dialysis fluid, in patients with inactive UC discontinuing SAZ therapy, might predict a relapse and thus improve medical decision making. Patients with UC in complete remission, maintained on SAZ for at least one 
year, therefore, entered a double blind placebo controlled trial on the efficacy of $\mathrm{SAZ}$, if $\mathrm{PGE}_{2}$ concentrations rose above control levels.

\section{Methods}

PATIENTS

Patients fulfilling the following entry criteria were candidates for the study: (a) proven UC on the basis of symptoms, endoscopic findings, histology of the rectal mucosa, and radiologic appearance, in addition to an exclusion of infectious diarrhoea by stool cultures and microscopy; ${ }^{12}$ (b) inactive disease (remission) for at least 12 months during maintenance treatment with SAZ (Salazopyrin, Pharmacia AB, Uppsala, Sweden) 2 g/day. Patients were considered in remission when symptom-free - that is, stool frequency $2 \times$ a day, without discharge of blood, pus, or mucus from the rectum, with normal sigmoidoscopic appearance, and with no significant inflammation on rectal biopsy. ${ }^{5}$ "

The study was done in accordance with the Helsinki Declaration II and approved by the Ethical Committee of Funen and Vejle Counties. Informed consent was given by all participants.

\section{EXPERIMENTAL DESIGN}

Equilibrium in vivo dialysis of faeces as well as equilibrium in vivo dialysis of rectum were done in consenting patients fulfilling the entry criteria. Subsequently, SAZ was stopped and the patients were free of medication. Evaluation of clinical disease activity, in addition to sigmoidoscopy with rectal biopsies for assessing endoscopic and histologic disease activity, ${ }^{1013}$ were done at scheduled visits after two weeks, after two, six, and 12 months, and in between, if indicated by recurrence of colitic symptoms. A relapse was defined as a recurrence of colitic symptoms accompanied by endoscopic signs of inflammation. If a relapse occurred the patient was withdrawn. At the scheduled visits also in vivo dialysis measurements were carried out. If faecal $\mathrm{PGE}_{2}$ concentrations and/or rectal $\mathrm{PGE}_{2}$ concentrations exceeded control levels - that is, faecal $\mathrm{PGE}_{2}$ $>0.5 \mathrm{ng} / \mathrm{ml} ;$ rectal $P G_{2}>1.0 \mathrm{ng} / \mathrm{ml}-$ at any study day the patient was allocated at random to double blind maintenance treatment with SAZ (tablets $0.5 \mathrm{~g}$; two tablets bid) or placebo tablets (two tablets bid) of identical appearance for six months. The SAZ and placebo tablets were provided by Pharmacia $A B$, Uppsala, Sweden. The randomisation was done according to a computer generated list in blocks of four, stratified for visit (two weeks, two months, six months, 12 months). In randomised patients a final visit was scheduled after six months of randomisation for in vivo dialysis measurements and for assessment of clinical, endoscopic, and histologic disease activity in case a relapse had not occurred earlier.

To minimise the variation between observers ${ }^{14}$ each patient was examined on all study days by the same investigator, who was unaware of the results of the dialysis measurements.

A laboratory screening was carried out on all study days and included blood haemoglobin, sedimentation rate, leucocyte count, leucocyte differential count, platelet count, and serum concentrations of creatinine and orosomucoid.

Thus patients completed the trial either (a) after 12 months of passive observation (in cases with normal $\mathrm{PGE}_{2}$ concentrations throughout); (b) six months after randomisation (in case $\mathrm{PGE}_{2}$ concentrations exceeded control levels); or (c) inbetween, if a relapse occurred.

Results obtained in the cohort of randomised patients served to evaluate the primary purpose of the study, that is, to test the predictive value of 'an increase in $\mathrm{PGE}_{2}$ levels' for experiencing a relapse in patients with inactive UC off SAZ treatment. Indirectly, in this design the named cohort also appeared to re-evaluate the efficacy of SAZ in maintaining remission.

IN VIVO DIALYSIS METHODS

Equilibrium in vivo dialysis of faeces was carried out as previously described in detail," by pooling the contents of five swallowed dialysis bags after their intestinal transit (faecal dialysate). These dialysates were analysed for concentrations of $\mathrm{PGE}_{2}$ (faecal $\mathrm{PGE}_{2}$ ) and leucotriene $\mathrm{B}_{4}$ (faecal $\mathrm{LTB}_{4}$ ).

Equilibrium in vivo dialysis of rectum was done after insertion of a $12-\mathrm{cm}$-long dialysis bag into the emptied rectum as previously described. ${ }^{10}$ The bag was left for four hours when it was removed and its contents (rectal dialysate) were analysed for concentrations of $\mathrm{PGE}_{2}\left(\right.$ rectal $\mathrm{PGE}_{2}$ ) and leucotriene $\mathrm{B}_{4}$ (rectal $\mathrm{LTB}_{4}$ ).

\section{ANALYTICAL PROCEDURES}

Prostaglandin $E_{2}$ was measured as previously described in detail ${ }^{15}$ by a radioimmunological method validated by gas chromatography mass spectrometry. ${ }^{16}$ The method, using 10-100 $\mu$ l samples, included addition of ${ }^{3} \mathrm{H}$-labelled $\mathrm{PGE}_{2}$ (Amersham International, Buckinghamshire, UK) as an internal standard, acidification, extraction with ethylacetate/ cyclohexane $(1: 1)$, and chromatography on microcolumns of Sephadex LH-20 (Pharmacia AB, Uppsala, Sweden) before performing the radioimmunoassay itself on the eluate fraction. The detection limit, defined as the procedure blank value $+2 \mathrm{SD}$, was $0.03 \mathrm{ng} / \mathrm{ml}$.

Leucotriene $\mathrm{B}_{4}$ was measured by using a com- 
mercially available antibody (Wellcome Diagnostics, Dartford, UK). The procedure, using 100-250 $\mu \mathrm{l}$ samples, included addition of ${ }^{3} \mathrm{H}$-labelled $\mathrm{LTB}_{4}$ (Amersham International, Buckinghamshire, UK) as an internal standard, acidification, extraction with dichloromethane/cyclohexane (2:3), and isolation of $\mathrm{LTB}_{4}$ by chromatography on Sephadex LH-20 microcolumns before the radioimmunoassay was performed on the eluate fraction. The detection limit, defined as the procedure blank value $+2 \mathrm{SD}$, was $0 \cdot 2 \mathrm{ng} / \mathrm{ml}$.

Further evaluations of the radioimmunological procedures for determination of $\mathrm{PGE}_{2}$ and $\mathrm{LTB}_{4}$ in 'rectal dialysates' were performed by comparing data obtained by simultaneous analysis of aliquots of the same samples (obtained from patients with active UC and controls) by radioimmunoassay and quantitative high pressure liquid chromatography for $\mathrm{PGE}_{2}$ and LTB $_{4}$, respectively. These validations are described elsewhere. ${ }^{17}$

All organic solvents were from Merck, Darmstadt, FRG.

The results were expressed as $\mathrm{ng} / \mathrm{ml}$ of colonic fluid. In 10 healthy controls the following results have previously been obtained: ${ }^{11}{ }^{17}$ Faecal $\mathrm{PGE}_{2}<0.5 \mathrm{ng} /$ $\mathrm{ml}$; faecal LTB $4<0.5 \mathrm{ng} / \mathrm{ml}$; rectal $\mathrm{PGE}_{2}<0.6 \mathrm{ng} / \mathrm{ml}$; rectal $\mathrm{LTB}_{4}<0.5 \mathrm{ng} / \mathrm{ml}$.

STATISTICAL ANALYSIS

Fisher's exact test was used for analysis of four-fold tables. ${ }^{18}$ A value of $\mathrm{p}<0.05$ was considered significant.

\section{Results}

DESCRIPTION OF PATIENTS

Twenty four patients consecutively entered the trial within an 18 month period. Another three patients fulfilled the entry criteria, but refused participation. One patient recruited for the study was withdrawn because revision of her records showed that she had
Crohn's disease. Table 1 describes characteristics of the 23 eligible patients.

\section{PROSTAGLANDIN E 2 CONCENTRATIONS IN \\ FAECAL AND RECTAL DIALYSATES}

Table 2 lists the faecal and rectal $\mathrm{PGE}_{2}$ concentrations in patients randomised to sulphasalazine or placebo. In 11 patients faecal $\mathrm{PGE}_{2}$ concentrations exceeded $0.5 \mathrm{ng} / \mathrm{ml}$ (six cases) or rectal $\mathrm{PGE}_{2}$ concentrations exceeded $1.0 \mathrm{ng} / \mathrm{ml}$ (all 11 cases) after withdrawal of SAZ: in six cases at two weeks; in one case at two months; in two cases at six months; and in two cases at 12 months (Table 2). Six of these patients were randomised to $\mathrm{SAZ}$ and five were randomised to placebo. The outcome of the disease within the six month treatment period is also shown in Table 2 . In the $S A Z$ group none of the six patients experienced a relapse and $\mathrm{PGE}_{2}$ concentrations decreased toward control levels. By contrast, four of five patients in the placebo group experienced a relapse $(p<0.05)$, Fisher's exact test).

Twelve patients remained non-randomised and ten of these experienced a relapse (Table 3 ). Retrospectively: in two cases (both relapsing within two weeks after cessation of SAZ treatment) $\mathrm{PGE}_{2}$ concentrations were increased at entry (Table 3: no 1 and 3); in four cases (Table 3: no 6, 9, 11, and 13) the $\mathrm{PGE}_{2}$ concentrations increased more than two-fold, but did not reach the randomisation levels. The $\mathrm{PGE}_{2}$ concentrations persisted within control levels in the patients not randomised and not experiencing a relapse (Table 3: no 7 and 21).

\section{LEUCOTRIENE B 4 CONCENTRATIONS IN FAECAL} AND RECTAL DIALYSATES

The faecal and rectal $\mathrm{LTB}_{4}$ concentrations were determined in all dialysates. These measurements were not included in the protocol describing the prospective study, why the data were subjected to a retrospective analysis. In most patients the faecal and rectal $\mathrm{LTB}_{4}$ concentrations were below the detection

Table 1 Selected characteristics of 23 patients with inactive ulcerative colitis

\begin{tabular}{|c|c|c|c|c|}
\hline & \multirow{2}{*}{$\begin{array}{l}\text { Recruited } \\
(n=23)\end{array}$} & \multicolumn{2}{|c|}{ Randomised* } & \multirow{2}{*}{$\begin{array}{l}\text { Non- } \\
\text { randomised } \\
(n=12)\end{array}$} \\
\hline & & $S A Z(n=6)$ & Placebo $(n=5)$ & \\
\hline Sex, male/female & $11 / 12$ & $4 / 2$ & $2 / 3$ & $5 / 7$ \\
\hline Duration disease, median month (range) & $72(18-480)$ & $84(36-480)$ & $108(24-192)$ & $66(18-228)$ \\
\hline Duration remission, median month (range) & $16(12-72)$ & $15(12-24)$ & $22(12-72)$ & $12(12-72)$ \\
\hline Duration of SAZ treatment, median month (range) & $60(12-144)$ & $48(20-120)$ & $60(24-144)$ & $57(12-132)$ \\
\hline Previously treated with corticosteroids (n) & 23 & 6 & 5 & 12 \\
\hline Smokers/non-smokers (n) & $4 / 19$ & $3 / 3$ & $1 / 4$ & $0 / 12$ \\
\hline Extension of disease $\dagger$, 'total'/left sided/rectal (n) & $6 / 10 / 7$ & $0 / 4 / 2$ & $3 / 1 / 1$ & $3 / 5 / 4$ \\
\hline
\end{tabular}

*Randomised because of increased faecal and/or rectal concentrations of $\mathrm{PGE}_{2}$; + Based on previous barium enema. 
Table 2 Faecal and rectal $P G E_{2}$ concentrations and outcome in 11 patients with inactive ulcerative colitis in whom sulphasalazine was stopped at entry. Randomisation to sulphasalazine or placebo was done because of increased $P G E_{2}$ concentrations

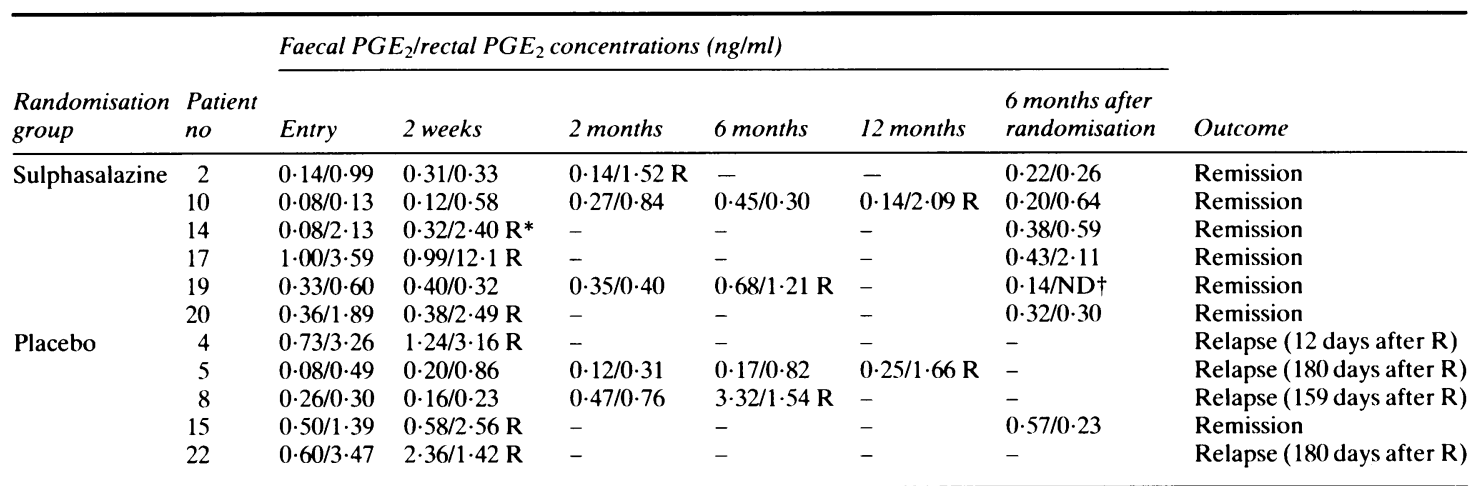

${ }^{*} R$, randomisation - that is, in case faecal $P_{G E}>0.5 \mathrm{ng} / \mathrm{ml}$ and $/$ or rectal $P G E_{2}>1.0 \mathrm{ng} / \mathrm{ml} ; \uparrow N D$, not done.

limit $(<0 \cdot 2 \mathrm{ng} / \mathrm{ml})$. Eleven patients were randomised because of abnormally increased $\mathrm{PGE}_{2}$ concentrations (as described above): In six cases the faecal $\mathrm{PGE}_{2}$ concentrations exceeded control levels $(0.5 \mathrm{ng})$ $\mathrm{ml})$, but only in a single case $\mathrm{LTB}_{4}$ concentrations were raised: in 11 cases rectal $\mathrm{PGE}_{2}$ concentrations exceeded the randomisation level $(1.0 \mathrm{ng} / \mathrm{ml})$, but only in five cases simultaneously increased $\mathrm{LTB}_{4}$ levels were observed. Similarly, $\mathrm{LTB}_{4}$ concentrations did not exceed control levels in the patients not randomised.

CLINICAL OUTCOME

The patient distribution and clinical outcome is summarised in the Figure. All relapses were proven by histology of rectal biopsies. In all patients remission was reinstated: In seven cases by resuming SAZ treatment $2-3 \mathrm{~g} /$ day orally; in six cases by resuming SAZ 2-3 g/day orally, in addition to topical treatment with corticosteroids, for two to eight weeks; and in a single case after prolonged treatment with systemic corticosteroid, in addition to SAZ.

\section{Discussion}

The present results suggest that an increased $\mathrm{PGE}_{2}$ concentration in rectal dialysis fluid determined by equilibrium in vivo dialysis of rectum heralds a relapse in patients with inactive UC. First, in patients randomised (because of increased $\mathrm{PGE}_{2}$ concentrations) four of five allocated to placebo experienced a relapse. By contrast, six similar patients resuming SAZ remained in remission and at their subsequent visit had shown a decrease toward control levels in

Table 3 Faecal and rectal $P G E_{2}$ concentrations and outcome in 12 patients with inactive ulcerative colitis in whom sulphasalazine was stopped at entry. These patients were observed passively because randomisation to sulphasalazine or placebo was not indicated by the protocol

\begin{tabular}{|c|c|c|c|c|c|c|}
\hline \multirow[b]{2}{*}{ Patient no } & \multicolumn{5}{|c|}{ Faecal $P G E_{2} /$ rectal $P G E_{2}$ concentrations $(\mathrm{ng} / \mathrm{ml})$} & \multirow[b]{2}{*}{ Outcome } \\
\hline & Entry & 2 weeks & 2 months & 6 months & 12 months & \\
\hline 1 & $0 \cdot 34 / 8 \cdot 41$ & - & - & - & - & Relapse (day 14) \\
\hline 3 & $0 \cdot 91 / 26 \cdot 1$ & - & - & - & - & Relapse (day 14) \\
\hline 6 & $0 \cdot 08 / 0 \cdot 20$ & $0 \cdot 14 / 0 \cdot 15$ & $0 \cdot 10 / 0 \cdot 46$ & $0 \cdot 42 / 0 \cdot 71$ & - & Relapse (day 295) \\
\hline 7 & $0 \cdot 20 / 0 \cdot 41$ & $0 \cdot 14 / 0 \cdot 49$ & $0 \cdot 03 / 0 \cdot 19$ & $0 \cdot 28 / 0 \cdot 67$ & $0 \cdot 46 / 0 \cdot 19$ & Remission \\
\hline 11 & $0 \cdot 09 / 0 \cdot 12$ & $0 \cdot 05 / 0 \cdot 10$ & $0 \cdot 24 / 0 \cdot 29$ & $0 \cdot 12 / 0 \cdot 30$ & - & Relapse (day 358) \\
\hline 12 & $0 \cdot 24 / 1 \cdot 26$ & $0 \cdot 24 / 0 \cdot 46$ & - & - & - & Relapse (day 56) \\
\hline 13 & $\mathrm{ND}^{*} / 0 \cdot 47$ & $0 \cdot 23 / 0 \cdot 31$ & $0 \cdot 30 / 0 \cdot 95$ & - & - & Relapse (day 81) \\
\hline 16 & $0 \cdot 20 / 0 \cdot 55$ & $0 \cdot 32 / 0 \cdot 24$ & - & - & - & Relapse (day 60$)$ \\
\hline 18 & $0 \cdot 37 / 0 \cdot 50$ & $0 \cdot 42 / 0 \cdot 22$ & $0 \cdot 34 / 0 \cdot 31$ & - & - & Relapse (day 156) \\
\hline 21 & $0 \cdot 22 / 0 \cdot 46$ & $0 \cdot 18 / 0 \cdot 34$ & $0 \cdot 16 / 0 \cdot 35$ & $0 \cdot 30 / 0 \cdot 27$ & $0 \cdot 27 / 0 \cdot 55$ & Remission \\
\hline 23 & $0 \cdot 65 / 2 \cdot 21$ & $0 \cdot 30 / 0.99$ & $0 \cdot 31 / 0 \cdot 99$ & - & - & Relapse (day 150) \\
\hline
\end{tabular}

*ND, not done. 

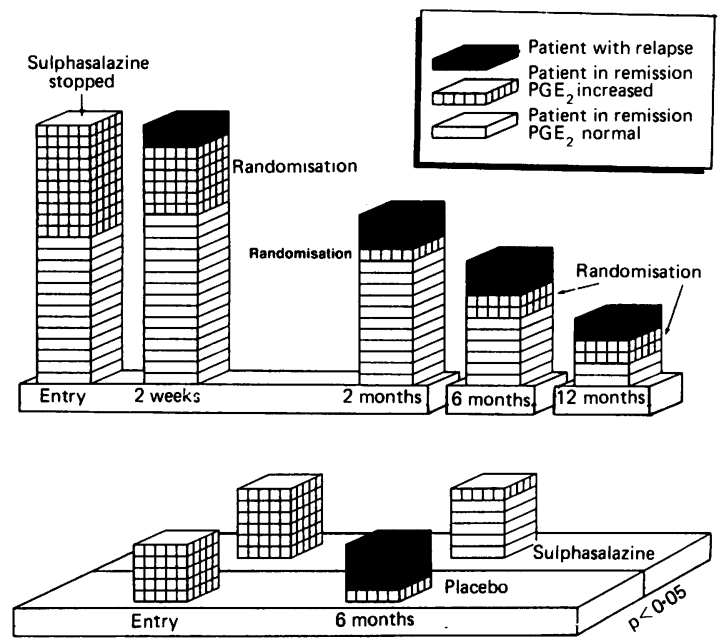

Figure Summary of patient distribution and clinical outcome. Upper panel: recruitment of patients for randomisation study; lower panel: randomisation study.

PGE $_{2}$ concentrations. Second, in two patients, who relapsed within 14 days after cessation of SAZ therapy, the $\mathrm{PGE}_{2}$ concentrations proved to have exceeded control levels at entry. Finally, in no case the demonstration of a normal $\mathrm{PGE}_{2}$ value was followed by an immediate relapse - that is, within two weeks. The observation, however, that only two patients observed passively completed the observation period of 12 months in remission, shows that the 'lack of an increase in $\mathrm{PGE}_{2}$ concentration' is only predictive in the short term for maintaining remission. Hence to improve decision making and to limit the risk of a relapse in patients off SAZ treatment more frequent dialysis collections than performed in the present protocol are required. For compliance reasons this may, however, reduce the suitability of the procedure for patient care.

The faecal and rectal $\mathrm{PGE}_{2}$ concentrations determined by the methods of equilibrium in vivo dialysis of faeces ${ }^{11}$ and equilibrium in vivo dialysis of rectum, ${ }^{10}$ respectively, appear sensitive markers of disease activity. ${ }^{10}$ In patients with inactive UC an increased $\mathrm{PGE}_{2}$ concentration in luminal dialysis fluid may indicate a mucosal abnormality, even in the absence of conventional signs of inflammation. ${ }^{11}$ The present data show that the rectal dialysis method is more sensitive than the in vivo dialysis of faeces: In all but one case (Table 2) the detection of an increased faecal $\mathrm{PGE}_{2}$ concentration $(>0.5 \mathrm{ng} / \mathrm{ml})$ was associated with a concomitant increase in the rectal $\mathrm{PGE}_{2}$ concentration $(>1.0 \mathrm{ng} / \mathrm{ml})$ and in no case a patient was randomised because of an increased faecal (but a normal rectal) $\mathrm{PGE}_{2}$ concentration. On the other hand, an increased rectal $\mathrm{PGE}_{2}$ concentration was often accompanied by a normal faecal $\mathrm{PGE}_{2}$ concentration (Table 2). This may be of clinical relevance, because outpatients experience the collection of stools more tedious than the performance of equilibrium in vivo dialysis of rectum. The retrospective analysis of the $\mathrm{LTB}_{4}$ data did not suggest any superiority of this variable for decision making in patients with inactive UC discontinuing SAZ.

The incidence of relapse observed among patients off SAZ therapy in the present series is in keeping with previous results, which have shown a relapse rate of $55 \%{ }^{5}$ and $69 \%^{1}$ over six months, and $75 \%$ over 12 months. ${ }^{1}$ Furthermore, the present data are in agreement with the findings of Dissanayake and Truelove, ${ }^{5}$ and later confirmed elsewhere, ${ }^{6-9}$ that SAZ is superior to placebo or other remedies, such as a high fibre $\operatorname{diet}^{6}$ or mast cell stabilisers, ${ }^{7-9}$ in maintaining remission in UC in the long term.

Based on the present data it might be argued that all patients with inactive UC should stay on SAZ indefinitely, because the relapse rate was high. The recurrences experienced in the present series, however, were easily handled in most cases, the courses being uncomplicated. Therefore, the duration of SAZ treatment in patients with inactive UC must also reflect other aspects of relapse preventing intervention than recurrence rates - for example, potential prognostic gains, side effects, costs, in addition to patients' own expectations and wishes. ${ }^{19}$ The latter is sometimes expressed as a keen desire to stop longstanding medication. The present study describes a method for predicting a relapse in those who prefer to discontinue SAZ. The data show that an increased $\mathrm{PGE}_{2}$ concentration in rectal dialysis fluid identify patients with a substantial risk of relapsing. Only a few experience prolonged remission, however, which is the reason why frequently repeated measurements are warranted.

This work was presented, in part, at the American Gastroenterological Assocation meeting in Chicago, Ill, USA 1987 (Gastroenterology 1987; 88: 1494 [Abstract]). We thank Pharmacia AB, Uppsala, Sweden, who kindly supplied the sulphasalazine and placebo, cand pharm Birgitte Secher, Hospital Pharmacy, Odense University Hospital for administering the drug code, Grete Eskesen, Anne Hallander, Dorit Ibsen, Inge-Lise Løffval, and Lene Persson for providing excellent technical assistance, and Rigmor Petersen for skilful secretarial assistance.

\section{References}

1 Misiewicz JJ, Lennard-Jones JE, Connell AM, Baron JH, Avery Jones FA. Controlled trial of sulphasalazine 
in maintenance therapy for ulcerative colitis. Lancet 1965 ; i: $185-8$.

2 Riis P. A critical survey of controlled studies in the treatment of ulcerative colitis and Crohn's disease. Clin Gastroenterol 1980; 9: 351-69.

3 Peppercorn MA. Sulphasalazine. Pharmacology, clinical use, toxicity, and related new drug development. Ann Intern Med 1984; 101: 377-86.

4 Riis P, Anthonisen P, Wulff HR, Folkenborg O, Bonnevie $\mathrm{O}$, Binder $\mathrm{V}$. The prophylactic effect of salazosulphapyridine in ulcerative colitis during longterm treatment: a double-blind trial on patients asymptomatic for one year. Scand J Gastroenterol 1973; 8: 71-4.

5 Dissanayake AS, Truelove SC. A controlled therapeutic trial of long-term maintenance treatment of ulcerative colitis with sulphasalazine (Salazopyrin). Gut 1973; 14: 923-6.

6 Davies PS, Rhodes J. Maintenance of remission in ulcerative colitis with sulphasalazine or a high-fibre diet: a clinical trial. Br Med J 1978; i: 1524-5.

7 Dronfield MW, Langman MJS. Comparative trial of sulphasalazine and oral sodium cromoglycate in the maintenance of remission in ulcerative colitis. Gut 1978; 19: 1136-9.

8 Willoughby CP, Heyworth MF, Piris J, Truelove SC. Comparison of disodium cromoglycate and sulphasalazine as maintenance therapy for ulcerative colitis. Lancet 1979; i: 119-22.

9 Davies PS, Rhodes J, Counsell B, Evans BK. Maintenance of remission in ulcerative colitis: effect of an orally absorbed mast cell stabilizer. Am J Gastroenterol 1980; 74: $150-3$.

10 Lauritsen K, Laursen LS, Bukhave K, Rask-Madsen J. Effects of topical 5-aminosalicylic acid and prednisolone on prostaglandin $E_{2}$ and leukotriene $B_{4}$ levels determined by equilibrium in vivo dialysis of rectum in relapsing ulcerative colitis. Gastroenterology 1986; 91: 837-44.

11 Lauritsen K, Hansen J, Bytzer P, Bukhave K, RaskMadsen J. Effects of sulphasalazine and disodium azodisalicylate on colonic $\mathrm{PGE}_{2}$ concentrations determined by equilibrium in vivo dialysis of faeces in patients with ulcerative colitis and healthy controls. Gut 1984; 25: 1271-8.

12 Binder V, Both H, Hansen PK, Hendriksen C, Kreiner $S$. Torp-Pedersen $K$. Incidence and prevalence of ulcerative colitis and Crohn's disease in the county of Copenhagen, 1962 to 1978. Gastroenterology 1982; 83: 563-8.

13 Binder V. A comparison between clinical state, macroscopic and microscopic appearances of rectal mucosa, and cytologic picture of mucosal exudate in ulcerative colitis. Scand J Gastroenterol 1970; 5: 627-32.

14 Baron JH, Connell AM, Lennard-Jones JE. Variation between observers in describing mucosal appearances in protocolitis. Br Med J 1961; i: 89-93.

15 Bukhave K, Rask-Madsen J. Prostaglandin $E_{2}$ in jejunal fluids and its potential diagnostic value for selecting patients with indomethacin-sensitive diarrhoea. Eur J Clin Invest 1981; 11: 191-7.

16 Bukhave K, Gréen K, Rask-Madsen J. Comparison of radioimmunological determination with gas chromatography mass spectrometry dosage. A study of $\mathrm{PGE}_{2}$ and $\mathrm{PGF}_{2 \alpha}$ in gastrointestinal fluids. Biomed Mass Spectrom 1983; 10: 265-8.

17 Lauritsen K, Laursen LS, Bukhave K, Rask-Madsen J. In vivo profiles of eicosanoids in ulcerative colitis, Crohn's colitis, and Clostridium difficile colitis. Gastroenterology 1988; 95: 11-7.

18 Fleiss JL. Statistical methods for rates and proportions. New York: John Wiley, 1981.

19 Riis P. Therapy of ulcerative colitis - a critical evaluation. Scand J Gastroenterol 1983; 18 [Suppl 88]: 24-9. 